\title{
Contemporary Management of Pulmonary Sequestration
}

\author{
Yasser Ali Kamal* \\ Department of Cardiothoracic Surgery, Egypt
}

Received: April 04, 2018; Published: May 16, 2018

*Corresponding author: Yasser Ali Kamal, Department of Surgery, Minia Cardiothoracic University Hospital, El Minia El Jadeda, 61519, Egypt; Tel: 002-01123234736; Fax: 002-0862342501; Email: yaser_ali_kamal@yahoo.com

\begin{abstract}
Pulmonary sequestration (PS) is a rare congenital lung malformation presented as non-functioning lung mass, abnormally supplied by an aberrant systemic artery. The diagnosis of PS requires a high index of clinical suspicion. Patients may be asymptomatic or have wide range of clinical manifestations including recurrent pneumonia, hemoptysis, chest pain and respiratory distress. The gold standard diagnostic tool of PS is CT angiography (CTA). The treatment includes open surgical resection, video-assisted thoracoscopic surgery (VATS), and endovascular embolization. This mini-review highlights the literature for the contemporary methods of diagnosis and treatment of PS.
\end{abstract}

Keywords: Lung malformations; Pulmonary sequestration; Video-assisted thoracoscopic surgery; Endovascular embolization

\section{Introduction}

Pulmonary sequestration (PS) accounts for $0.15-6.4 \%$ of pulmonary malformations, and it is a considered as one of the surgically correctable causes of respiratory distress in neonates [1]. It represents non-functioning parenchyma mass covered by visceral pleura and supplied by anomalous systemic arteries [2]. As a developmental malformation, PS results from formation of an abnormal accessory lung bud inferior to the normal lung buds [3]. There are two main subtypes of PS: intralobar sequestration (ILS) and extralobar sequestration (ELS), in accordance to presence of pleural covering [4]. The cases of ILS account for more than $75 \%$ of all PS [3]. Extralobar PS is frequently located between the left lower lobe and diaphragm, and for rare instances it may locate intraadiaphragamtic, infradiaphragmatic, intraabdominal, intrapericardial, mediastinal or in the upper thoracic region. In contrast to ILS, more than $50 \%$ of ELS cases have other pulmonary anomalies such as bronchogenic cysts, lung hypoplasia, congenital cystic adenomatoid malformation, and congenital diaphragmatic hernia $[5,6]$.

\section{Diagnosis of PS}

Antenatal, ultrasound is a useful tool for diagnosis of PS starting at 18 weeks of gestational age. It has been recommended as the first diagnostic modality to evaluate a suspected supraphrenic pulmonary mass, because it is simple, non-invasive, non-radioactive and can be done as a bed-side procedure $[6,7]$. The substantial or complete regression of the lesion on sequential scanning has been reported through pregnancy. The postnatal persistence of the lesion requires further imaging procedures to delineate the aberrant blood supply [6]. However, antenatal PS may disappear on ultrasound but still present by postnatal CT, as it becomes isoechogenic with adjacent normal lung parenchyma [7]. After birth, the diagnosis of PS requires a high index of suspicion. There is a frequent misdiagnosis of PS by pulmonary cyst and lung cancer. The reported mean of incorrect preoperative diagnosis rate is $58.63 \%$ [8]. In misdiagnosed cases, the interval between initial symptoms and diagnosis may exceed 5 years. Despite the current advent and use of more accurate imaging modalities, recent studies reported only $37.5 \%$ of cases diagnosed before surgery [9].

Most of cases with PS are diagnosed before the age of 20 years. Pediatric patients acquired symptoms more frequently than the adult patients. Patients with ILS often present with productive cough, fever, hemoptysis and chest pain as a result of pulmonary infections, however, ELS is accidentally discovered in asymptomatic patients $[8,10]$. Pulmonary infection is a common complication of PS, however, symptoms of infection are misinterpreted as common infection as it can be a presenting complaint for lung tumors, chronic obstructive pulmonary disease, or tuberculosis [11]. The cultured microorganisms of concurrent infection with PS include: Pseudomonas aeruginosa, nocardia and aspergillosis [9].

Patients with PS may present with manifestations related to its mass effect. Recently, a case of multiloculated-multiseptated pneumomediastinum with ELS has been reported, that is explained by "Macklin effect" which is the centripetal dissection of released air from ruptured alveoli defining the passage of air through perivascular spaces [12]. The routine evaluation of pulmonary function in patients of PS is not required, however, the contemporary available evaluation of FEV1 in adults revealed 
the possibility of mild to moderate obstructive ventilation dysfunction due to smoking, PS itself and/or concurrent infection [9].

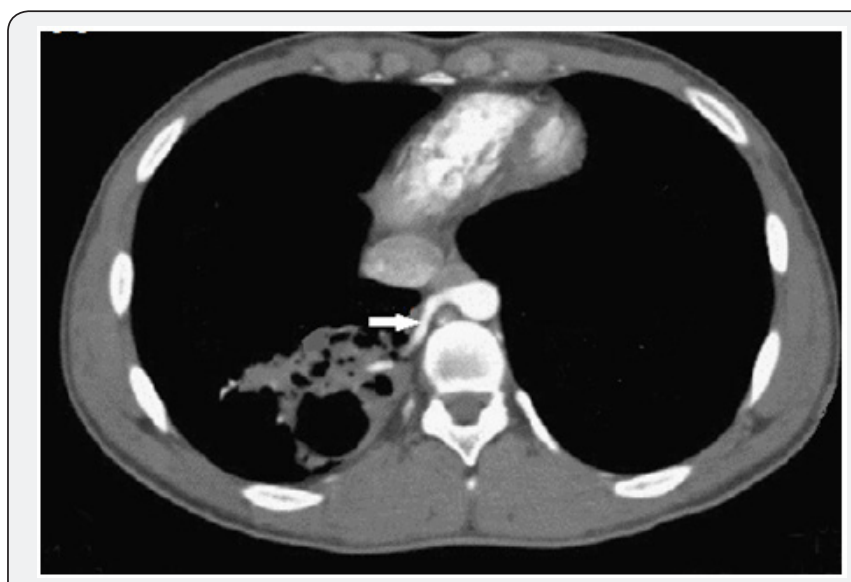

Figure 1: An axial view of contrast-enhanced chest computed tomography (CT) shows a feeding artery arises from the descending aorta (arrow) and enters a sequestrated mass at the right lower lobe.

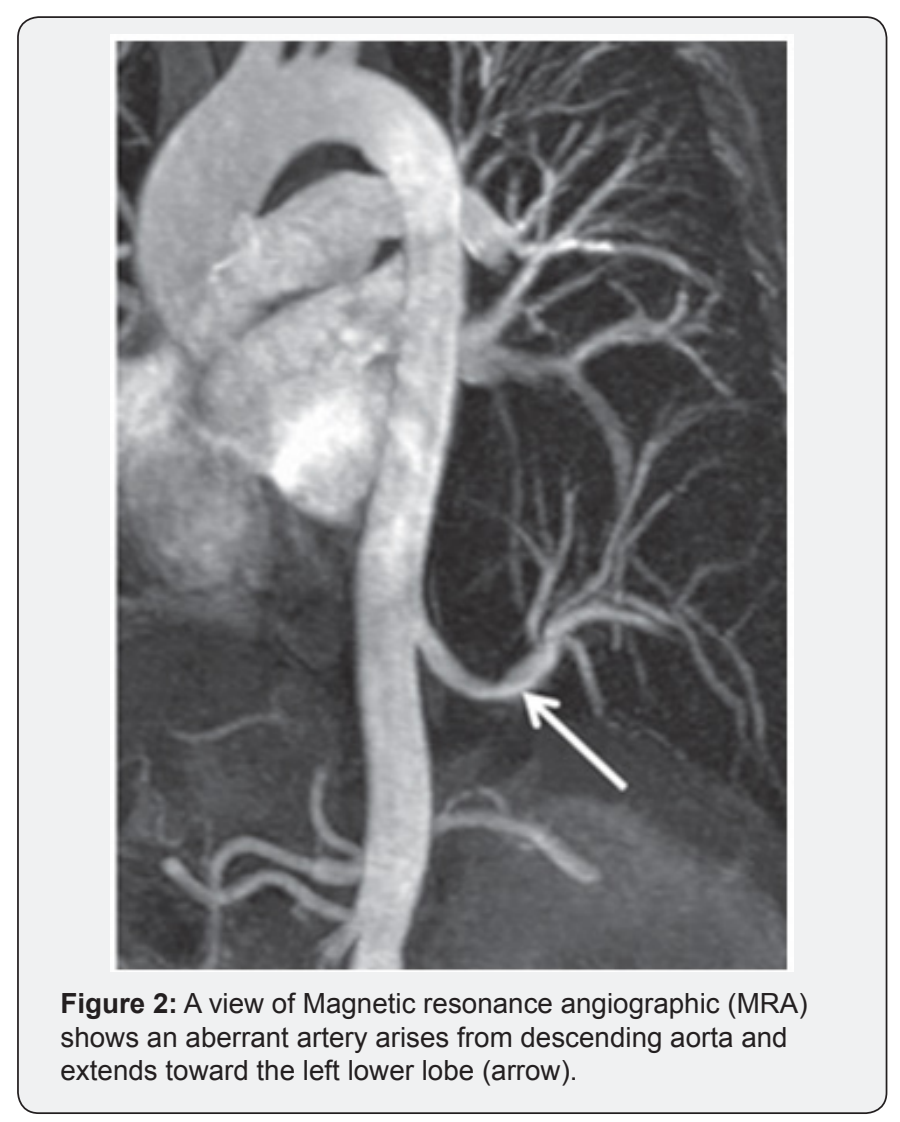

On imaging studies for PS, there may be no specific findings on chest X-ray examination, however, there may be a pulmonary abnormality which is usually solid opacity and occasionally it may be air filled with or without air fluid level due to fistula formation to adjacent bronchi or air drift through the channels of Lambert $[13,14]$. Nowadays, the useful diagnostic methods of
PS are CT angiography (CTA), magnetic resonance angiography (MRA), and digital subtraction angiography (DSA) which allow identification of the aberrant arterial supply (Figures $1 \& 2$ ) [8].

The standard computed tomography (CT) scan may show indirect signs of abnormal arteries in cases with PS, which may indicate further use of contrast-enhanced CT scan or enhanced MRI if the affected pulmonary area and thoracic aorta are connected by rat-tailed tissue. The use of CTA has the advantage of an optimal detection of the parenchymal abnormality as well as the arterial and venous anatomy with shorter scan times than those of MRI decreasing the need for prolonged sedation in children; however, MRI has an advantage of the absence of radiation risks [15].

Coronary angiography may be a part of diagnostic workup for PS, in adult patients present with chest pain or worsening dyspnea. Cases of PS with abnormal supply from the right or the circumflex coronary artery have been described, including cases of unilateral PS fed by both arteries or bilateral PS supplied by abnormal vessels originating separately from each artery $[15,16]$. Coronary angiography in such cases is important to avoid intraoperative ligation of the feeding vessels from coronary artery and to prevent subsequent fatal outcome.

\section{Treatment of PS}

A controversy remains about the choice between observation and surgical management of asymptomatic PS, however, the most frequent decision is for surgical resection to avoid the unfavorable outcomes of subsequent infection and hemorrhage [17]. In symptomatic patients, surgery is indicated for recurrent pulmonary infection or when cancer is not excluded. Mass resection is sufficient for ELS, while lobectomy is required for ILS, with an attention to suture all abnormal arterial blood supply [8]. In cases of severe infected ILS, segmentectomy or ligation of the aberrant artery is not sufficient with a favor for lobectomy to avoid contamination [18]. However, some authors reported the feasibility of sublobar resections (wedge resection or anatomical segmentectomy), particularly for limited basal segment locations, which depend on delimitation of PS and surgeon experience [19].

Timing of surgery for PS remains controversial. However, early surgery is argued before the age of 5 years to avoid compression of PS mass on the new formed or growing alveoli. Presence of symptoms, rapid growth of PS and difficult to distinguish PS from CCAM are acceptable indications of early surgical resection [20]. The surgical resection can be performed through open postero-lateral thoracotomy or via video-assisted thoracic surgery (VATS). Currently, VATS has been proved as a safe and effective procedure for the surgical resection of PS, with advantages of smaller incision, quicker recovery, and better cosmetic outcomes over the open procedure [8].

The presence of pleural adhesions has not been an absolute contraindication of VATS. It can be separated under direct 
visualization with identification and ligation of the abnormal arterial supply, which provide clear surgical field [21]. Moreover, the emerging uniportal VATS approach has been used for resection of ELS and complete lobectomy in cases with ILS, even with multiple feeding arteries and extensive post-inflammatory adhesions [22]. Reducing the rate of postoperative complications after VATS resection of PS can be achieved by: preoperative full anti-inflammatory therapy for cases with acute or sub acute inflammation, careful dissection and isolation of the abnormal systemic feeding artery to avoid its rupture and bleeding, securing the aberrant arteries by ligation, clipping or both before applying of the endo-stapler, preoperative prediction of the number and position of the aberrant arteries by enhanced CT scan and 3-D reconstruction with extension of the view under the diaphragm to detect arteries arising from the abdominal aorta, avoiding the injury of esophagus if it is interlinked with ELS, and conversion of VATS to the open procedure if there are severe adhesions or vascular injuries [21,22].

Robot-assisted thoracoscopic resections have been reported to provide encouraging outcomes in management of certain intra-thoracic pathologies, which can be applied for cases with PS with no complications or mortality [23-26]. The contemporary reported favorable outcome with robot-assisted thoracoscopic resections of ILS is attributed to its better manageability and view, which is ideal in limited spaces. It has a useful role in PS cases of difficult dissection and aberrant artery control, allowing safe sublobar resection and reducing the risk of vascular injury [26].

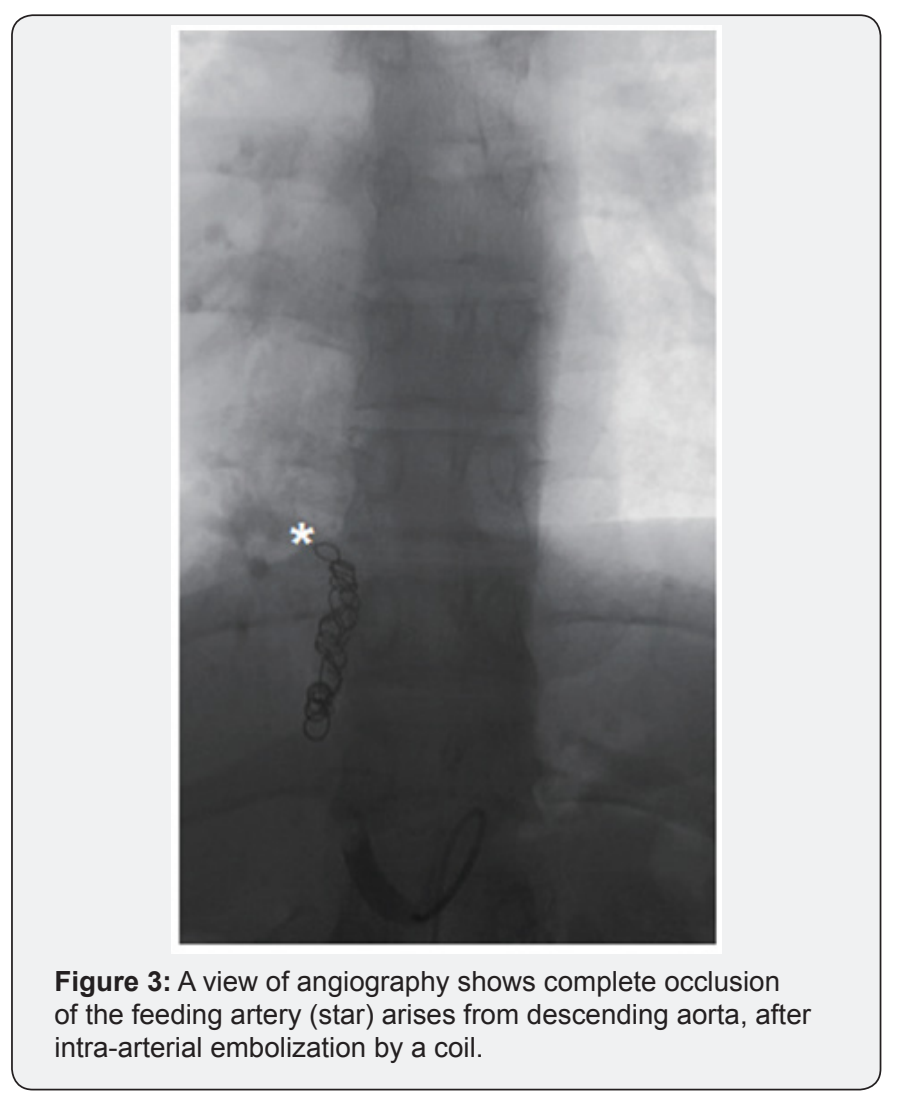

The basis of endovascular embolization for PS is related to infarction of the sequestrated mass subsequent to progressive fibrosis of the dysplastic lung tissue and feeding vessel after occlusion of the arterial blood supply (Figure 3). Embolization has been reported as a non-invasive definitive treatment of ILS with reduced the risk of intra-operative bleeding, in children and young adult patients [27]. With an evidence of ILS and arteriovenous shunting and heart failure, embolization has been reported as a successful alternative to surgery, while surgical resection is a preferred strategy for cases with recurrent chest infection $[27,28]$.

Combination of embolization with surgery has been reported to prevent intra-operative bleeding as preoperative embolization obliterates the aberrant artery which may be friable due to chronic inflammation leading to massive bleeding if the surgery stands alone [29]. However, there is a need for more experience and long-term follow up to suggest the ability of embolization as a stand-alone treatment and as an alternative to surgery [30]. The currently used materials for embolization in PS include: coils, vascular plugs, N-butyl cyanoacrylate, gelfoam, Amplatzer occlusion device, polyvinyl alcohol and Onyx [27,31].

Despite its encouraging results, endovascular embolization had potential complications include: fever, pain, transient hypertension, access site thrombosis, transient limb ischemia, distant migration, non-target embolization, incomplete mass regression, and pediatric risk of radiation exposure. There may be a need to repeat the procedure for incomplete embolization associated with recurrence of symptoms. The feeding artery may be occluded after embolization but the formation of collateral blood supply may lead to incomplete embolization [27,31].

\section{Conclusion}

To reduce the rate of misdiagnosis and to improve the outcome after treatment, there should be a clear strategy of diagnosis and treatment of PS. In the contemporary practice, surgical resection of PS is preferred regardless of the presence of symptoms. A controversy remains regarding the long-term outcomes after surgery and endovascular embolization.

\section{References}

1. Coutinho DJ, Dias MC, Oliveira MJ, Vaz DC, Shiang MT (2015) Bronchopulmonary sequestration presenting as a spontaneous pneumothorax. Respir Care 60(3): e59-e61.

2. Liang C, Xu S, Zhao B, Ma G, Du Y (2015) Primary pulmonary sequestration with secondary hamartomatosis change. Iran J Radiol 12(3): e11591.

3. Qian X, Sun Y, Liu D, Wu X, Wang Z, et al. (2015) Pulmonary sequestration: a case report and literature review. Int J Clin Exp Med 8(11): 21822-21825.

4. Sun X, Xiao Y (2014) Pulmonary sequestration in adult patients: a retrospective study. Eur J Cardiothorac Surg 48(2): 279-282.

5. Lee JH, Kim MJ (2014) Intradiaphragmatic extralobar pulmonary sequestration in adult. J Cardiothorac Surg 9:112.

6. Yilmaz A, Bektemur G, Ekinci GH, Ongel EA, Kavas M, et al. (2013) 
Extralobar pulmonary sequestration: a case report. Monaldi Arch Chest Dis 79(2): 90-92.

7. Zhang H, Tian J, Chen Z, Ma X, Yu G, et al. (2014) Retrospective study of prenatal diagnosed pulmonary sequestration. Pediatr Surg Int 30(1): 47-53.

8. Wei Y, Li F (2011) Pulmonary sequestration: a retrospective analysis of 2625 cases in China. Eur J Cardiothorac Surg 40(1): e39-e42.

9. Gompelmann D, Eberhardt R, Heussel CP, Hoffmann H, Dienemann H, et al. (2011) Lung sequestration: a rare cause for pulmonary symptoms in adulthood. Respiration 82(5): 445-450.

10. Palmowski M, Schreiner K, Hansmann J, Grenacher L (2007) Bronchopulmonary sequestration: a differential diagnosis in young adults for recurrent pneumonia. The Lancet 369(9569): 1318.

11. Unal S, Turkyılmaz C, Derinkuyu BE, Aktaş S, Ergenekon E, et al. (2016) Mass effect of pulmonary sequestration: Multiloculated multiseptated pneumomediastinum. J Neonatal Surg 5(2): 18.

12. Chan CLS, Ng DKK, Lu PP, Chong ASF, PKH Tam PKH (2003) Pulmonary sequestration in an Infant. HK J Paediatr (new series) 8: 43-46.

13. Lee DI, Shim JK, Kim JH, Lee HY, Yun YK, et al. (2008) Pulmonary sequestration with right coronary artery supply. Yonsei Med J 49(3): 507-508.

14. Lin CH, Chuang CY, Hsia JY, Lee MC, Shai SE, et al. (2013) Pulmonary sequestration differences in diagnosis and treatment in a single institution. J Chin Med Assoc 76(7): 385-389.

15. Falsini G, Porto I, Rosa I, Liistro F, Amidei S, et al. (2013) Bilateral intralobar pulmonary sequestrations receiving separate arterial supply from the right and circumflex coronary arteries: a case report. Int J Cardiol 166(1): e12-e13.

16. Wani SA, Mufti GN, Bhat NA, Baba AA (2015) Pulmonary sequestration: early diagnosis and management. Case Reports in Pediatrics 454860.

17. Hirai S, Hamanaka Y, Mitsui N, Uegami S, Matsuura Y (2007) Surgical treatment of infected intralobar pulmonary sequestration: a collective review of patients older than 50 years reported in the literature. Ann Thorac Cardiovasc Surg 13(5): 331-334.

18. Konecna J, Karenovics W, Veronesi G, Triponez F (2016) Robot-assisted segmental resection for intralobar pulmonary sequestration. Int J Surg Case Rep 22: 83-85.

19. Cho MJ, Kim DY, Kim SC, Kim KS, Kim EA, et al. (2012) Embolization versus surgical resection of pulmonary sequestration: Clinical experiences with a thoracoscopic approach. J Pediatr Surg 47: 22282233.

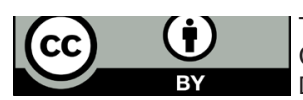

This work is licensed under Creative Commons Attribution 4.0 License DOI: 10.19080/OAJS.2018.09.555756
20. Shen JF, Zhang XX, Li SB, Guo ZH, Xu ZQ, et al. (2013) Complete videoassisted thoracoscopic surgery for pulmonary sequestration. J Thorac Dis 5(1): 31-35.

21. Sihoe ADL, Luo Q, Shao G, Li Y, Li J, et al. (2016) Uniportal thoracoscopic lobectomy for intralobar pulmonary sequestration. J Cardiothorac Surg 11: 27.

22. Al-Mufarrej F, Margolis M, Tempesta B, Strother E, Gharagozloo F (2009) Robot-assisted thoracoscopic resection of intralobar sequestration. J Laparoendosc. Adv Surg Tech A 19(3): 389-391.

23. Melfi FM, Viti A, Davini F, Mussi A (2011) Robot-assisted resection of pulmonary sequestrations. European Journal of Cardio-thoracic Surgery 40:1025-1026.

24. Gulkarov I, Ciaburri D, Tortolani A, Lazzaro R (2012) Robotic thoracoscopic resection of intralobar sequestration. J Robot Surg 6(4): 355-357.

25. Konecna J, Karenovics W, Veronesi G, Triponez F (2016) Robot-assisted segmental resection for intralobar pulmonary sequestration. Int J Surg Case Rep 22: 83-85.

26.Zener R, Bottoni D, Zaleski A, Fortin D, Malthaner RA, et al. (2017) Transarterial embolization of intralobar pulmonary sequestration in a young adult with hemoptysis. J Thorac Dis 9(3): E188-E193.

27. Brown SC, De Laat M, Proesmans M, De Boeck K, Van Raemdonck D, et al. (2012) Treatment strategies for pulmonary sequestration in childhood: resection, embolization, observation? Acta Cardiol 67(6): 629-634.

28. Avsenik J, Stupnik T, Popovic P (2015) Endovascular embolization prior to surgical resection of symptomatic intralobar pulmonary sequestration in an adult. Eur J Radiol Open 3: 12-15.

29. Ojha V, Samui PP, Dakshit D (2015) Role of endovascular embolization in improving the quality of life in a patient suffering from complicated intralobar pulmonary sequestration-A case report. Respiratory Medicine Case Reports 16: 24-28.

30. Gursu AH, Boyvat F, Varan B, Erdogan I (2014) Embolization of pulmonary sequestration with Onyx: an unusual application. Turk Kardiyol Dern Ars 42(2):174-177.

31. Leoncini G, Rossi UG, Ferro C, Chessa L (2011) Endovascular treatment of pulmonary sequestration in adults using Amplatzer ${ }^{\circledR}$ vascular plugs. Interact Cardiovasc Thorac Surg 12(1): 98-100.

\begin{tabular}{l} 
Your next submission with Juniper Publishers \\
will reach you the below assets \\
- Quality Editorial service \\
- Swift Peer Review \\
- Reprints availability \\
- E-prints Service \\
- Manuscript Podcast for convenient understanding \\
- Global attainment for your research \\
- Manuscript accessibility in different formats \\
( Pdf, E-pub, Full Text, Audio) \\
- Unceasing customer service \\
Track the below URL for one-step submission \\
https://juniperpublishers.com/online-submission.php \\
\hline
\end{tabular}

